Mathematical Problems of Computer Science 53, 67--71, 2020.

UDC 004

\title{
The Concept of Internal IP Addresses System for NRENs
}

\author{
Robert N. Tadevosyan, Arthur S. Petrosyan and Gurgen S. Petrosyan \\ Institute for Informatics and Automation Problems of NASRA \\ e-mail: robert@sci.am, arthur@sci.am, gurgen@sci.am
}

\begin{abstract}
This paper presents the concept of a new system of internal IP addresses proposed for use by National Research and Education Networks (NREN). Recently, various systems and services, have been actively developing, such as Wi-Fi, IP telephony, etc., for which it is necessary to ensure the security of streams, reducing the area of collisions, etc. The allocation of additional IP addresses in local networks makes it possible to realize all the abovementioned tasks and have the necessary reserve for future development. The concept is deployed in Academic Scientific Research Computer Network of Armenia (ASNET-AM).
\end{abstract}

Keywords: VLAN, Networking, eduroam, Wi-Fi, VoIP

\section{Introduction}

In general, the Virtual Local Area Network (VLAN) technology is used to logically divide the network into different and independent parts. The proposed concept of IP addressing distribution system to subnets and methods of implementation with appropriate VLANs technology for managing and controlling them, suggest a completely new vision to this technology. It takes into account many factors of the current development of National Research and Education Networks (NRENs) (the detailing is outside the scope of this work, since it may vary for different NRENS), network infrastructure, installed devices and the specifics of the connected institutions. In addition, the presented concept allows flexible future growth of NREN infrastructure. The proposed concept of IP addressing distribution promotes the development of virtually unlimited additional services in NREN in the future without any big changes and reorganization of the network structure.

As a rule of thumb, Local Area Network (LAN) internal IP addressing system has the following simple scheme without any logical division and VLANs implementations. For each 
connected institute, one "C" class of internal IP addresses is allocated. Addresses are distributed from the pool of addresses reserved for private use [1], such as prefixes 192.168/16, 172.16/12 and 10/8. As an example several LAN addresses may be used according to the following system: "10.1.X.Y", where " $X$ " is the allocated organization number in the IP space (in the third byte), and " $\mathbf{Y}$ " is the space of $\mathbf{2 5 6}$ addresses, for use in the internal local networks.

\section{Concept Architecture}

For each organization connected to NREN, a new IP address space can be allocated for " $\mathbf{B}$ " class network and will be built according to the following scheme: "10.X.Y.Y", where " $\mathrm{X}$ " is the allocated Institution number in IP space, and "Y.Y" are spaces of 256 "C" class addresses (65536 IP addresses) for use in the internal local networks. To save the current IP numbering system of organizations, the organization numbers will be moved from the third byte to the second one: “10.1.X.Y” - “10.X.Y.Y”. Networks started from 10.200.Y.Y will be used for addressing the globally controlled communication devices.

Each Institution of " $\mathrm{B}$ " class network will be divided into logical and physical subspaces according to the following principle.

1. Workstations

2. Local servers

3. Managed communication equipment within the organization, etc.

4. Wi-Fi devices

5. Voice over Internet Protocol (VoIP) phones

6. ... for future use

At the moment, it is proposed to use the first 128 networks of institutions address spaces. The remaining 128 networks will be reserved for further expansion of network systems and services. The distribution of IP addressing will be carried out according to the following scheme:

-10.X.0-A.Y - Desktops

-10.X.A+1-B.Y - Local Servers

-10.X.B+1-C.Y - Local Managed Communication Equipment

-10.X.C+1-G.Y - Wi-Fi devices

-10.X.G+1-H.Y - VoIP phones

Additionally, the subnet "10.X.C+1-G.Y - Wi-Fi devices" is proposed to be divided into subparts according to the type and area of use of the connected devices as follows:

- 10.X.C+1-D.Y - The general academic Wi-Fi network devices (SSID: eduroam)

- 10.X.D+1-E.Y - Wi-Fi network of current organization (for example, SSID: IIAP)

-10.X.E+1-F.Y - Guest Wi-Fi access by the organization (for example, SSID: IIAPFreeWiFi)

-10.X.F+1-G.Y - Will be implemented if necessary (for example: SSID: CSIT2019)

The implementation of this new IP addressing system will be efficient through the creation of appropriate VLANs for each of the subnets [2]. The following systems of standards are proposed for internal names and numbering of VLANs:
$\checkmark$ 10.X.0-A.Y
- VLAN name: VLANZ00, VLAN id: Z00
$\checkmark$ 10.X.A+1-B.Y
- VLAN name: VLANZA+1, VLAN id: ZA+1
$\checkmark$ 10.X.B+1-C.Y
- VLAN name: VLAN ZB+1, VLAN id: $\mathbf{Z B + 1}$
$\checkmark$ 10.X.C+1-D.Y
- VLAN name: VLAN ZC+1, VLAN id: ZC+1
$\checkmark$ 10.X.D+1-E.Y
- VLAN name: VLAN ZD+1, VLAN id: ZD+1
$\checkmark$ 10.X.E+1-F.Y
- VLAN name: VLAN ZE+1, VLAN id: ZE+1 


$$
\begin{array}{lll}
\checkmark & \text { 10.X.F+1-G.Y } & \text { - VLAN name: VLAN ZF+1, VLAN id: ZF+1 } \\
\checkmark & \text { 10.X.G+1-H.Y } & \text { - VLAN name: VLANZG+1, VLAN id: ZG+1 }
\end{array}
$$

where $\mathbf{X}$ is the network number allocated to organizations in the IP subspace for the local network addresses of NREN.

\section{Internal IP Address Distribution System}

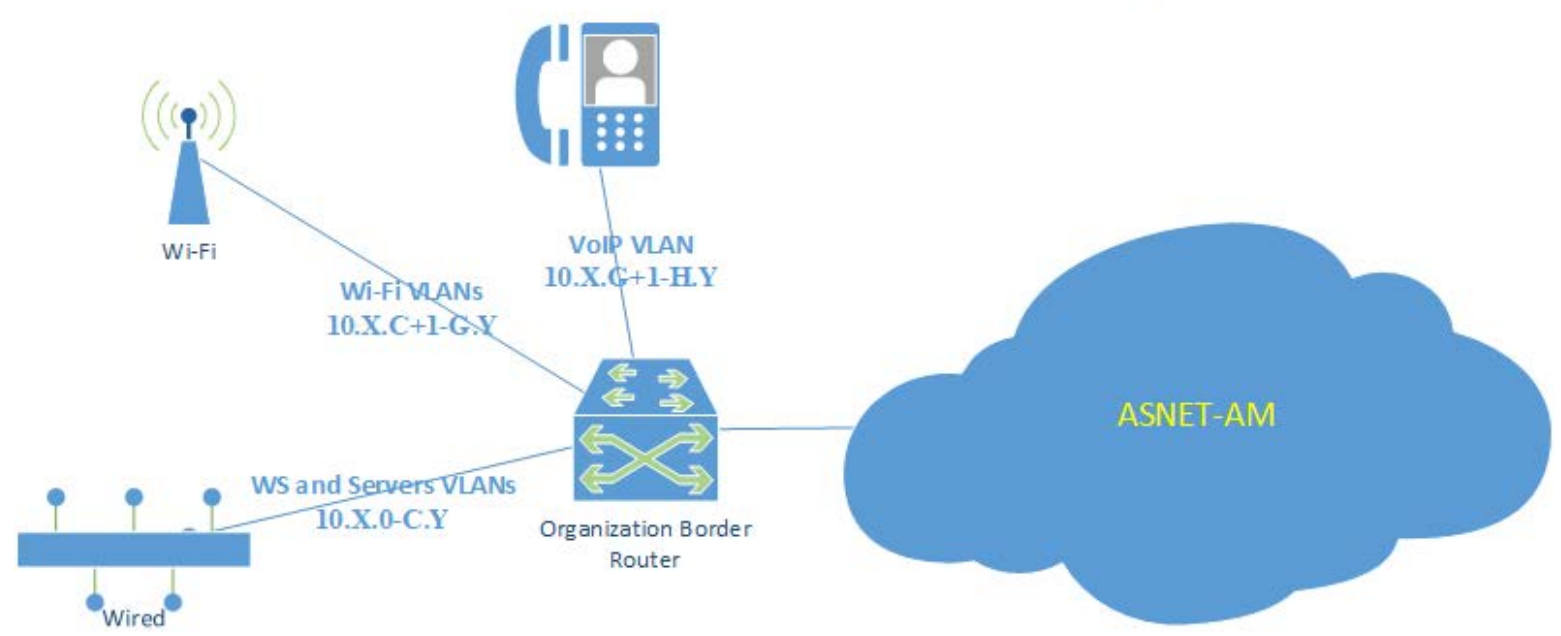

Fig. 1. Internal IP address distribution system.

For example, the VLAN number for workstations will be $\mathbf{Z 0 0}$, the VLAN number for general academic Wi-Fi network devices will be $\mathrm{ZC+1}$, and the VLAN number for the subnet of VoIP devices will be $\mathrm{ZG}+\mathbf{1}$.

Additionally, if it is necessary to divide the subnets to subparts and subVLANs, the numeration should be created according to the following scheme. An additional number from 0 to 9 should be added to the base VLAN number. For example, when it is necessary to create additional subnets and VLANs in "Workstations" zone, the numbers will be Z001, Z002, Z003, or ZA0, ZA1, etc.

The first number of VLANs for subnets started from 100 , will be $-\mathbf{Z}+\mathbf{1}$, and for subnets started from 200 , will be $-\mathrm{Z}+2$.

This is a general and theoretical vision of the new IP addressing system. Practical implementation includes the creation of a real numeration standard and distribution, as default, which will be implemented for all connected institutions. Implementation of this system as standard will facilitate easy configuring and managing the border routers of all connected institutions. Since the proposed IP addressing system does not conflict with the standard addressing space, it can be implemented without any interruption of the network work. To start this process in the connected institution, it is necessary to configure new address spaces and VLANs on the border router, and then, after starting to the step-by-step transition of all equipment and devices to the new addressing system.

In the pan-European data network for the research and education community (GÉANT) [3], which interconnects the NRENs across Europe, there are some proposals for internetworking VLANs implementations [4], but this work covers another area of work scope.

Currently, the proposed numbering and distribution system with the appropriate VLANs has already been created as a standard and enacted in production mode. This document with the default numbering system, is an internal document of the ASNET-AM network. 
The implementation of this new internal IP addressing system on the border routers of NREN-connected institutes will now allow the unimpeded expansion of network services and systems and create the basis for future growth.

\section{Conclusion}

The proposed concept can be used by any NREN to make the internal infrastructure more efficient. Currently, this new IP addressing system has already been implemented in the local networks of several Academic Scientific Research Computer Network of Armenia (ASNETAM)-connected organizations. In the mentioned Institutions, the production of Wi-Fi network structure is already divided into subnets with the corresponding Service Set Identifier (SSID) access. Each subnet operates in its own dedicated VLAN and receives, via the Dynamic Host Configuration Protocol (DHCP), IP addresses corresponding to its own VLAN, which allows the general control and regulation of flows, as well as access control to resources of both ASNET$\mathrm{AM}$ and the Internet [5].

In the future, this new addressing system will be expanded to all organizations connected to ASNET-AM.

\section{References}

[1] Y. Rekhter, B. Moskowitz, D. Karrenberg, G. J. de Groot and E. Lear, “Address allocation for private internets”, Silicon Graphics, Inc, February 1996, [Online]. Available: https://tools.ietf.org/html/rfc1918

[2] P. Congdon, M. Sanchez, B. Aboba, "RACIUS attibutes for virtual LAN and priority support”, [Online]. Available: https://www.ietf.org/rfc/rfc4675.txt

[3] [Online]. Available: https://www.geant.org/

[4] V. Capone and M. Usman , "The GÉANT network: addressing current and future needs of the HEP community”, Journal of Physics: Conference Series 664 052005, DOI:

10.1088/1742-6596/664/5/052005, 2015, [Online]. Available: https://iopscience.iop.org/article/10.1088/1742-6596/664/5/052005/pdf

[5] B. Hartpence, Routing and Switching, O’Reilly Media, Inc., ISBN: 9781449306557, 2011, [Online]. Available: https://www.oreilly.com/library/view/packet-guide-to/9781449311315/

Submitted 04.03.2020, accepted 18.06.2020. 


\title{
Ztinuqnunuluwi l lpponıpjuil uqqujhi guightph itepphi huugtiulnnưui huruwlqunqh lnighiughw
}

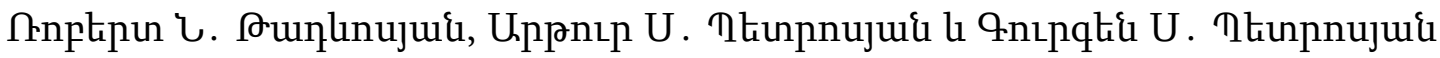

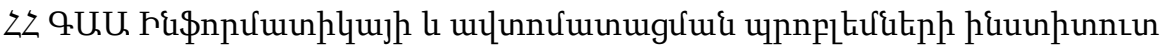 \\ El. huugt: robert@sci.am, arthur@sci.am, gurgen@sci.am
}

\begin{abstract}
Uự̧nนุnư

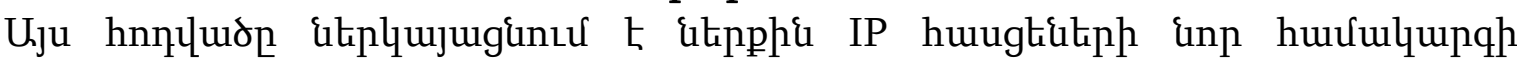

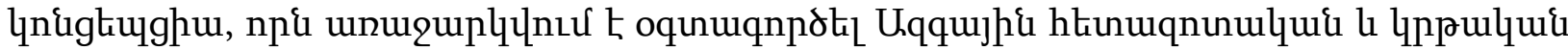

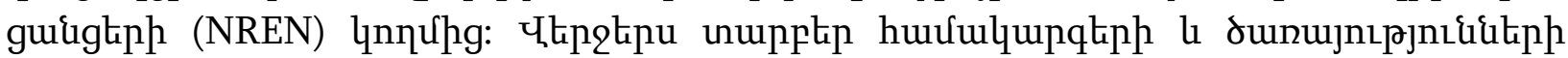

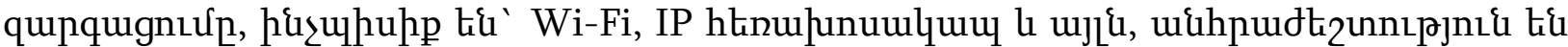

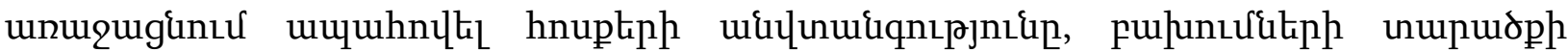

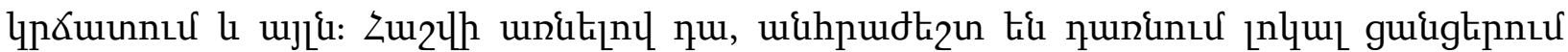

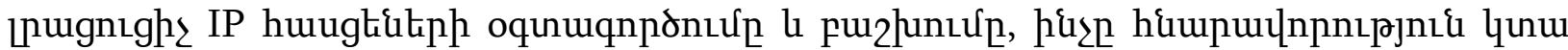

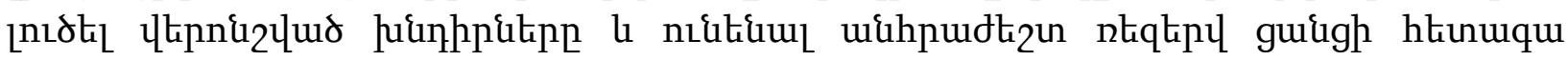

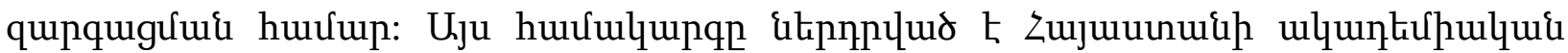

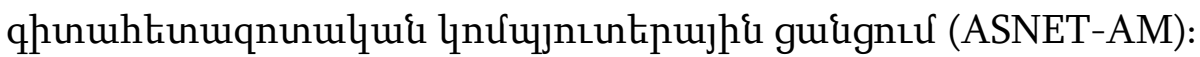

Fuiuulh puntin' VLAN, Networking, eduroam, Wi-Fi, VoIP

\section{Концепция системы внутренних IP адресов в локальных сетях для национальных научно-образовательных сетей}

\author{
Роберт. Н. Тадевосян, Артур С. Петросян и Гурген С. Петросян \\ Институт проблем информатики и автоматизации НАН РА \\ e-mail: robert@sci.am, arthur@sci.am, gurgen@sci.am
}

\begin{abstract}
Аннотация
В этом документе представлена концепция новой системы внутренних IP-адресов для использования национальными исследовательскими и образовательными сетями (NREN). В последнее время развитие различных систем и сервисов, таких как Wi-Fi, IP телефония и др., требуют обеспечения безопасности потоков в выделенных каналах, уменьшения коллизий, что создает потребность в дополнительных IP адресах. Эти IP адреса помогут устранить вышеперечисленные недостатки и обеспечат необходимый задел для будущего развития сети. Данная концепция уже внедрена в Академической научно-исследовательской компьютерной сети Армении (ASNET-AM).
\end{abstract}

Ключевые слова: VLAN, Networking, eduroam, Wi-Fi, VoIP. 